\title{
Evaluation of the role of gracilis free flap in reconstruction of orofacial defects
}

\author{
Original \\ Mohammed A. Morsi', Mohamed Mohamed Fata', Mohamed Hussein Warda', \\ Article \\ Ahmed Serag Eldin ${ }^{1}$ and Luca Calabrese ${ }^{2}$ \\ ${ }^{1}$ Department of Maxillofacial and Plastic Surgery, Faculty of Dentistry, \\ Alexandria University, Alexandria, Egypt, ${ }^{2}$ Department of Head and Neck Surgery, \\ European Inistitute of oncology, Milan, Italy
}

\begin{abstract}
Background: Microsurgical tissue transfer has constantly improved the therapeutic options for reconstruction in the head and neck region, but the ideal flap has yet to be found. The purpose of this study is to discuss the aesthetic and functional potential of the free gracilis muscle flap in difficult head and neck reconstruction.

Patients and Methods: We report our experience with the free gracilis muscle flap in eleven patients who underwent reconstruction in the head and neck region for a variety of indications.

Results: In all eleven patients, the transplanted muscle flaps healed well, with no flap loss. Postoperative complications consisted of donor-site morbidity that was minimal in all patients.

Conclusion: For difficult reconstruction in the head and neck region, the free gracilis muscle flap offers a number of advantages, including reliable vascular anatomy, relatively great plasticity and a concealed donor area. Thus this type of flap offers a valuable option whenever an aesthetically and functional pleasing result is sought.
\end{abstract}

Key Words: Free muscle transfer, gracilis free flap, orofacial defect, reconstruction.

Received: 07 October 2019, Accepted: 17 November 2019.

Corresponding Author: Mohamed A. Morsy, Department of Oral and Maxillofacial Surgery, Faculty of Dentistry, Alexandria University, Alexandria, Egypt, Mob.: +201221999131, E-mail: dr_morsi_80@hotmail.com.

ISSN: 2090-097X, January 2021, Vol. 12, No. 1

\section{INTRODUCTION}

Extensive tissue defects in the head and neck are a challenge for reconstructive surgery. Regardless the etiology of the defect is a resection for neoplasm, infection, osteoradionecrosis, congenital defect, or trauma, the goals and principles are similar; they are to restore adequate function and aesthetics and thereby improve the quality of life ${ }^{[1]}$.

In the $1950 \mathrm{~s}$, defects were repaired using a forehead flap or temporalis muscle flap combined with/without a split-thickness skin graft, but the long-term results showed a scarred forehead or temporal contour deformity ${ }^{[2]}$.

In 1965, Bakamjian ${ }^{[3]}$ started the use of the deltopectoral flap, and it was one of the most significant improvements in the era of head and neck reconstruction. The main disadvantage of the deltopectoral flap is the need to form an oral fistula and separate it during a second operation ${ }^{[4]}$.

The pectoralis major myocutaneous flap has been popular for head and neck reconstruction since 1979. However, it cannot reconstruct defects cranial to the midface due to the insufficient length of the pedicle ${ }^{[5,6]}$.

Composite head and neck reconstruction usually requires 3-dimensional reconstruction that can be best achieved by free tissue transfers. Continual refinements in microsurgical techniques and the use of various donor sites have increased the surgical options for extensive resections of advanced neoplasms of the head and neck.

Reconstruction of defects of the head and neck by using free flaps is significantly more demanding in respect of technical and financial aspect of flap harvesting itself, performing microvascular anastomosis, and subsequently prolonged operating time and a higher flap failure rate compared to pedicled flaps ${ }^{[7,8]}$.

The gracilis muscle or musculocutaneous flap has been the donor muscle preferred by many reconstructive microsurgeons. Depending on the indication, the gracilis flap can be used as a local flap based on its arc of rotation for local wound coverage or reconstruction. However, it is nowadays more often applied as a free flap for distant reconstruction ${ }^{[9]}$.

The gracilis flap is our first choice for the application of functioning free muscle transplantation [FFMT] for functional restoration or as a distant free flap only for skin and soft tissue coverage. Gracilis FFMT involves transfer of a fresh gracilis muscle to the face for a deficit, utilizing microvascular anastomoses for muscle revascularization and reinnervation, to allow the transferred gracilis muscle to become a functional muscle ${ }^{[10]}$. 


\section{MATERIALS AND METHODS}

This study included eleven cases with challenging soft tissue defects in the oro-facial region of various etiologic factors, without age or sex limitations. All patients were admitted to the department of Maxillo-Facial and Plastic Surgery, Faculty of Dentistry, Alexandria University, Egypt.

\section{Preoperative assessment and preparation}

All patients were subjected to the following:

\section{A. Patients complain and history:}

1. History of the present condition.

2. Personal habits especially cigarette smoking or alcohol consumption.

3. Previous exposure to radiation as therapeutic for orofacial tumors management.

4. History of vascular disease, diabetes mellitus, bleeding and coagulation disorders.

5. Previous history of drug intake (coagulopathy) e.g. aspirin, anticoagulant.

6. Previous history of drug allergies.

\section{B. Clinical examination:}

\section{Systemic examination:}

1. Vital signs.

2. Systemic review: cardiac, chest, abdominal, and limbs examination.

\section{Local examination:}

1. Staging of malignancies by TNM classification of head and neck cancer ${ }^{[11]}$.

2. Assessment of expected or existing bony and soft tissue defects. If bony defect was required to be reconstructed, this patient was excluded from this study.

3. Assessment of facial nerve paralysis by HouseBrackmann Classification of Facial Function ${ }^{[12]}$ (Table 1).

4. Clinical evaluation of the availability of other more suitable reconstructive options other than free tissue transfer.

5. Examination of the donor site for the presence of scar, previous operation, or trauma or vascular diseases (e.g.: varicose veins).

\section{Laboratory investigations:}

Routine blood examination which include blood group, complete blood picture, liver and renal function tests, fasting blood sugar, bleeding and coagulation time were done.
Specific blood investigations which include:

1. Prothrombin time and activity is highly important as it reflects the liver function state.

2. Serum albumin judges the free protein bind capacity

3. Bacteriological investigations: Wound or ulcerative tumour swab and sensitivity test for determination of the already present organisms and choosing the suitable antibiotics for each case.

Table 1: House-Brackmann Classification of Facial Function ${ }^{[12]}$,

\begin{tabular}{|c|c|}
\hline Grade & Manifestations \\
\hline I. Normal: & Normal facial function in all areas \\
\hline $\begin{array}{l}\text { II. Mild } \\
\text { dysfunction }\end{array}$ & $\begin{array}{l}\text { Gross: } \\
\text { Slight weakness noticeable on close } \\
\text { inspection. } \\
\text { May have slight synkinesis. } \\
\text { At rest, normal symmetry and tone. } \\
\text { Motion: } \\
\text { Forehead: Moderate to good function. } \\
\text { Eye: Complete closure with minimal effort. } \\
\text { Mouth: Slight asymmetry. }\end{array}$ \\
\hline $\begin{array}{l}\text { III. Moderate } \\
\text { dysfunction }\end{array}$ & $\begin{array}{l}\text { Gross: } \\
\text { Obvious but not disfiguring difference } \\
\text { between sides. } \\
\text { Noticeable (but not severe) synkinesis, } \\
\text { contracture, or hemifacial spasm. } \\
\text { At rest, normal symmetry and tone. } \\
\text { Motion: } \\
\text { Forehead: Slight to moderate movement. } \\
\text { Eye: Complete closure with effort. } \\
\text { Mouth: Slightly weak with maximum } \\
\text { effort. }\end{array}$ \\
\hline $\begin{array}{l}\text { IV.Moderately- } \\
\text { severe } \\
\text { dysfunction: }\end{array}$ & $\begin{array}{l}\text { Gross: } \\
\text { Obvious weakness and/or disfiguring } \\
\text { asymmetry. } \\
\text { At rest, normal symmetry and tone. } \\
\text { Motion: } \\
\text { Forehead: None. } \\
\text { Eye: Incomplete closure. } \\
\text { Mouth: Asymmetrical with maximum } \\
\text { effort. }\end{array}$ \\
\hline $\begin{array}{l}\text { V. Severe } \\
\text { dysfunction: }\end{array}$ & $\begin{array}{l}\text { Gross: } \\
\text { Only barely perceptible motion } \\
\text { At rest, asymmetry } \\
\text { Motion: } \\
\text { Forehead: None. } \\
\text { Eye: } \text { Incomplete closure. } \\
\text { Mouth: Slight movement. }\end{array}$ \\
\hline $\begin{array}{l}\text { VI. Total } \\
\text { paralysis: }\end{array}$ & No movement. \\
\hline
\end{tabular}

\section{Radiological examination:}

1. Dental pantogram if needed.

2. Ultrasound scans of the neck

3. Computerized tomography of the head, neck, chest, and upper abdomen with intravenous contrast in cases of malignant head and neck tumours. 


\section{E. Specific test:}

Electromyography (EMG) of facial nerve in case of facial nerve paralysis to assess motor function of facial muscles and facail nerve conduction.

Flap design:

Anatomic landmarks (Figure 1):

Palpate the tight adductor longus muscle first when the patient lies on the table and the medial thigh is abducted. The gracilis origin is located just superficially behind the adductor longus origin.

The gracilis muscle is long thin muscle that measures from 4 to $6 \mathrm{~cm}$ in width. The neurovascular pedicle enters the muscle 8 to $10 \mathrm{~cm}$ caudal to pubic tubercle (Figure 1).

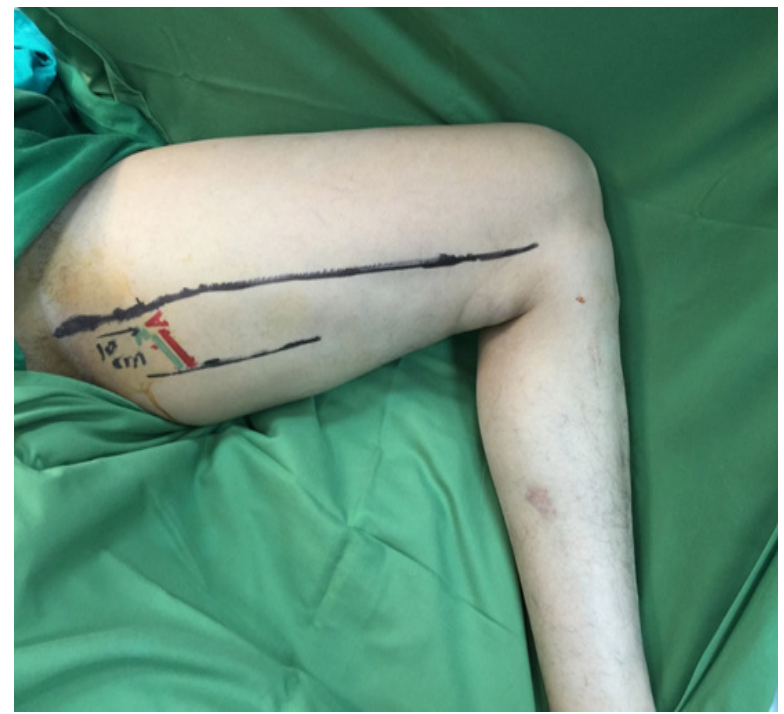

Figure 1: Flap design and incision line for harvest of gracilis muscle free flap.

The dominant musculocutanous perforators is also located in the same vicinity. Since the location of musculocutanous perforators is consistent we centered the skin paddle over the proximal third of gracilis muscle without meticulous dissection of perforators.

If the skin paddle is needed the flap is going to be harvested, the skin paddle can be outlined over the muscle or over the posterior edge of the adductor longus muscle where the intermuscular septum is located that carries perforator vessels to supply the overlying skin.

\section{Technique of flap harvest:}

\section{A. Skin paddle and gracilis muscle compound flap:}

Patient were placed in the supine position under general anesthesia, abduction of the thigh from which the flap were harvested.

Resection and flap harvest were taken place simultaneously and performed by two surgical teams.
The proximal gracilis muscle and its overlying skin paddle centralized at the vessel pedicle were marked the anterior skin incision was made down to the fascia of the adductor longus muscle and the entire fascia of the adductor is exposed.

The fascia over the adductor longus was incised longitudinally over the middle portion of the muscle and elevated posteriorly. The adductor longus muscle was retracted laterally. The main vascular pedicle and the anterior motor branch of the obturator nerve to the gracilis muscle were visualized .The intermuscular septum was included with the flap as it contains septocutaneous perforators that supply the overlying skin. The posterior incision was then made down through the subcutaneous tissue to the gracilis muscle and a thin skin flap was harvested.

The proximal gracilis musculocutaneous flap was then elevated cutting by diathermy . Many small musculocutaneous perforators not supplying skin paddle were coagulated with a bipolar coagulator and divided. The dissection is stopped once the medial septum was encountered.

The perforator vessels in the skin paddle and gracilis muscle compound flap are septum perforators with no need of intramuscular dissection.

\section{B. Gracilis muscle flap harvest:}

The gracilis muscle was just medial and inferior to the adductor longus muscle in the upper part about two finger breadth behind adductor line, which is aline from pubic tubercle to medial aspect of knee represent the surface anatomy odf adductor longus muscle.

The incision was directly deep to the deep fascia to expose the gracilis muscle. The proximal $10 \mathrm{~cm}$ length of muscle was then exposed. The part of the muscle to be used was dissected free from the surrounding structures. The motor nerve was identified and dissected as far as possible, usually up to the bifurcation of the obturator nerve or more proximally. The adductor longus muscle was retracted upward and laterally for easy nerve dissection proximally. The vessel was usually dissected proximal to the branch to the adductor longus. All branches going up to the adductor longus were coagulated or ligated, and divided. The muscle was safely split or trimmed by coagulation mode of diathermy.

\section{Preparation of the recipient site:}

\section{In cases of tumor resection:}

The resection surgical team prepared the recipient site by removing the diseased unhealthy tissue, excision of ulcer or malignant tumour(hemiglossectomy or near total glossectomy) with safety margin with neck dissection(unilateral or bilateral). The donor vessels were prepared for anastomosis with that of the recepient vessels (Figure 2). 

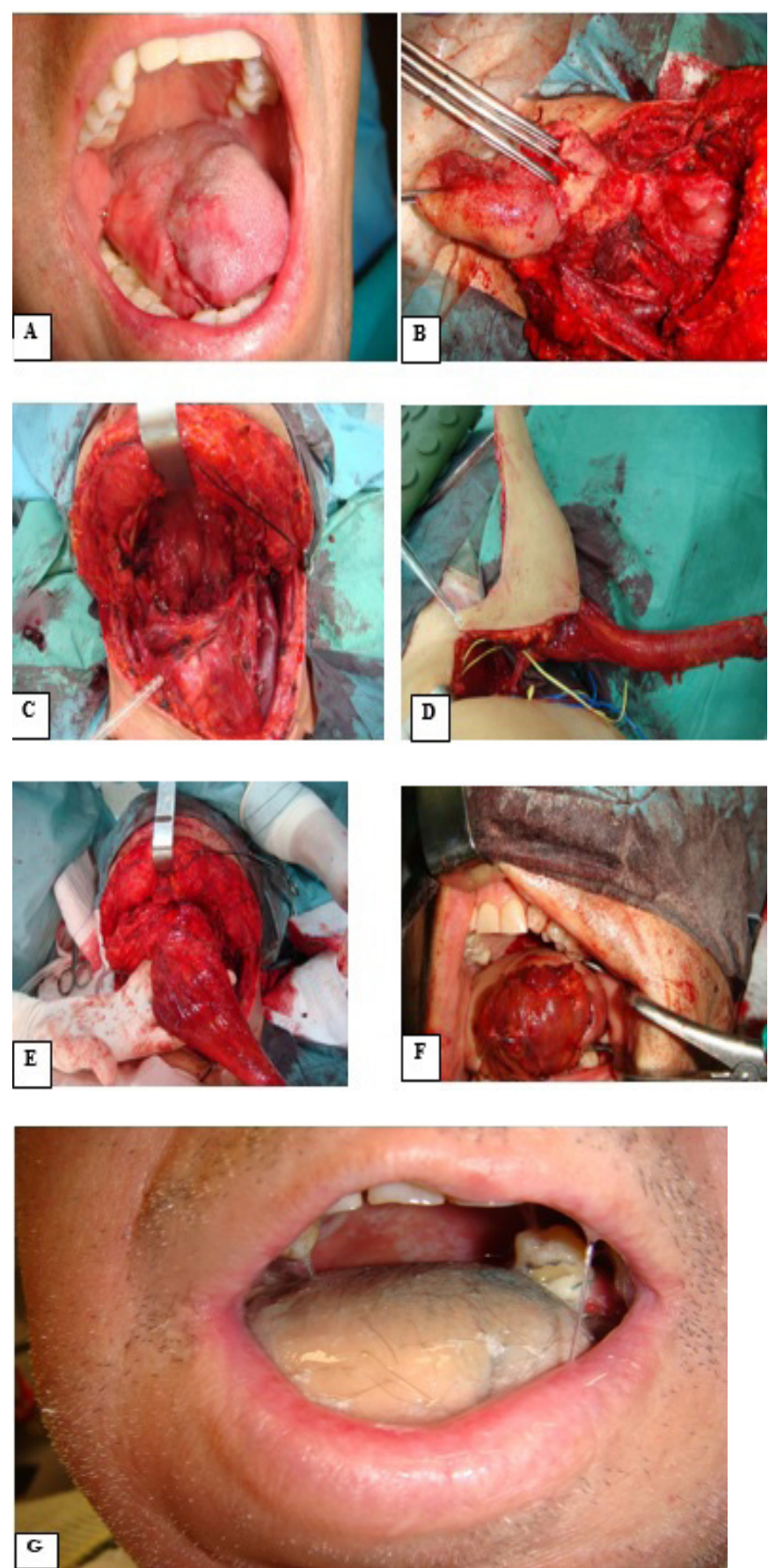

Figure 2: Patient no (1) with squamous cell carcinoma of right side of the tongue crossing midline:

A. SCC involved right side of tongue, crossed the midline to contralateral side of tongue and extended to base of tongue.

B. Intraoperative photos shows near totat glossectomy with partial resection of floor of mouth.

C. After radical resection and Bilateral modified neck dissection.

D. Transverse myocutanous gracilis(TMG) free flap.

E. Flap setting in floor of the mouth.

F. Reconstruction of tongue by skin paddle and muscle of TMG.

G. 3 months postoperatively showing eventual healing.

\section{In cases of facial nerve paralysis:}

The second surgical team prepared the donor vessel plus the recipient nerve (nerve to masseter) on same side of facial paralysis for end to end nerve anastomosis.

\section{Identification of nerve to masseter muscle:}

The anatomy of the motor nerve to the masseter was consistent. A convenient starting point for its dissection was found $3.16 \pm 0.30 \mathrm{~cm}$ anterior to the tragus at a level $1.08 \pm 0.18 \mathrm{~cm}$ inferior to the zygomatic arch. The nerve was located $1.48 \pm 0.19 \mathrm{~cm}$ deep to the superficial muscular aponeurotic system (SMAS) at this point.

The pedicle artery was ligated and ischemia time was recorded. The vein was then ligated. Intravenous Heparin 5000 IUwas administered before anastomosis. Heparinized saline $10 \mathrm{IU} / \mathrm{CC}$ was used for lavage of the artery and vein. The flap was then anchored to the recipient site by few stay sutures. The recipient site artery and vein were, also opened and washed with heparinised saline. 5000 IU heparin was given intravenously and anastomosis of the recipient and donor vessels was done usually starting with the artery using $80 /$ to $90 /$ Ethilon suture, then the vein was anastomosed using Ethilon 90/. The sutures were interrupted. Starting with arterial anastomosis allows choosing of the dominant venae commitant by releasing the clamps over the arterial anastomosis and comparing the amount of venous return from each venae commitant, this is especially useful in case of single venous anastomosis.

\section{Methods to test microvascular anastomosis by patency test and flap monitoring:}

An operating microscope Zeiss OPMI-6-SD-FC-XYwas used.

When anastomosis was completed, the distal clamp on the recipient artery was released, while small gauze was applied on the suture line. Next, the proximal clamp was released. Waiting for 5 minutes, and monitoring the flap perfusion, then the gauze was removed. Bleeding from the anastomotic line was observed and need for additional sutures were evaluated.

\section{Donor site closure:}

If the skin paddle was limited to a width slightly more than the gracilis muscle width, $5-8 \mathrm{~cm}$ in adults, the wound closed primarily. A wider skin paddle required undermining both skin flaps anteriorly and posteriorly for direct wound closure.

In cases of gracilis muscle flap was harvested without skin paddle direct closure of surgical wound without undermining was done.

\section{Postoperative management:}

After the operation the patient was transferred to the intensive care unit (I.C.U.). Extubation was performed, when the patient was fully conscious, on next day with 
stable vital measures, oxygen saturation and flap viability were good. The patient stayed in the ICU for 35- days where the postoperative treatment was given in the following regimen:

1. IV fluid infusion: the adult patient with average body weight and good liver, lung and renal functions usually takes 34- litres per 24 hours. Ringer lactate solution was continuously infused all around the 24 hours without stoppage (3050drops per minute) and was guided with the C.V.P. level. When the C.V.P. was less than $7 \mathrm{~mm} \mathrm{H} 2 \mathrm{O}$, it was essential to give the patient more I.V. fluid. This I.V. fluid regimen was reduced to 2 litres provided that there was good oral fluid intake and then it was stopped. Positive fluid balance was preferable for fear of thrombosis secondary to dehydration.

2. Feeding was started on second post-operative day orally in patients without oral involvement and through a naso-gastric tube in patients with oral involvement.

3. Anticoagulants: Clexan $40 \mathrm{mg}$ per 24 hours was given routinely to all patients during the first 57- days to avoid D.V.T. Heparin was not given routinely in every patient as it was only given in the following situations:

a- Intraoperative problematic anastomosis at which the anastomosis was not easy.

b- Free flap revision secondary to thrombosis either arterial or venous.

c- Past history of previous thrombosis or exposure to irradiation especially near the anastomosis.

4. Aspirin: Paediatric aspirin "75 mg" was given routinely once daily for each patient started from the first postoperative day and for 3 weeks.

5. Analgesics: Were given whenever indicated through IV line. Opioids were usually given in the first 3 days followed by non-steroidal antiinflammatory drugs whenever indicated. Pain sensation induces vasoconstriction which should be avoided in microvascular procedure.

6. Antibiotics: Systemic antibiotics were given with the induction of anaesthesia. Usually Augmentin $1.2 \mathrm{~g}$ was given the day of operation and the first 5 days.

7. Antacids and vitamins were given only when indicated.

8. Drains output monitoring and were removed if the output is less than $50 \mathrm{cc}$ in 24 hours.

\section{Follow up:}

The patient was usually discharged at the end of the second week and the following data were recorded during these follow up visits:

1. Subjective and objective evaluation of function and aesthetics.

2. Healing and fulfilment of the reconstructive options.

3. Donor site morbidity: infection, haematoma, seroma and resultant scar.

4. Photography of the donor and recipient sites.

\section{RESULTS}

In the period between September 2013 and December 2016 a total of eleven gracilis free flaps had been used for reconstruction of oro-facial defects in five patients and facial reanimation in six patients (Table 2).

Table 2: Distribution of the studied cases according to demographic data $(\mathrm{n}=11)$ :

\begin{tabular}{lccc}
\hline & No. & $\%$ \\
\hline Sex & & \\
Male & 7 & 63.6 \\
Female & 4 & 36.4 \\
Age (years) & & \\
Min. - Max. & \multicolumn{3}{c}{$16.0-63.0$} \\
\hline
\end{tabular}

\section{Indication of surgery:}

In 5 patients, the defects resulted following ablative surgery for locally advanced malignant tongue tumour ( $45.5 \%$ of patients), where the surgical defects were beyond local or regional flaps reconstruction. (Table 3 ) The pathology of these tumours was squamous cell carcinoma in the five patients (Table 3).

Table 3: Distribution of causes according to cause of defect $(\mathrm{n}=11)$

\begin{tabular}{ccc}
\hline Cause of defect & No. & \% \\
\hline Ablative surgery & 5 & 45.5 \\
$\begin{array}{c}\text { Facial nerve } \\
\text { paralysis }\end{array}$ & 6 & 54.5 \\
$\begin{array}{c}\text { Iatrogenic extra- } \\
\text { oral defect }\end{array}$ & 1 & 9.1 \\
\hline
\end{tabular}

The other, 6 patients were suffered from unilateral total facial nerve paralysis (54.5\%), in 3 patients the cause was bell's palsy, in 2 patients the cause was iatrogenic injury after excision of glomus tympanicum and in one patient $(9.1 \%)$ the cause of left facial nerve paralysis and soft tissue defect on left parotid region was previous surgery 
for resection of vascular lesion at the parotid area with reconstruction of the surgical defect by split thickness skin graft.

\section{Flap size and design:}

In our study the flap sizes ranged from $5 \times 7 \mathrm{~cm}$ $\left(35 \mathrm{~cm}^{2}\right)$ to $8 X 10 \mathrm{~cm}\left(80 \mathrm{~cm}^{2}\right)$ The largest flap was used to reconstruct tongue after near total glossectomy plus reconstruction of floor of the mouth in patient no.1.

According to flap design (Table 4) in our study we had reconstructed 6 cases by gracilis myocutanous free flap $(54.5 \%)$ and 5 cases were reconstructed by gracilis muscle free flap (45.5\%). All cases of gracilis myocutanous flap (6 cases) the skin paddle was transversly oriented to the muscle.

Table 4:

\begin{tabular}{ccc}
\hline Flap design & No. & \% \\
\hline With skin paddle & 6 & 54.5 \\
Without skin paddle & 5 & 45.5 \\
\hline
\end{tabular}

\section{Site of the defect: (Figure 3)}

In our study we had 5 cases with intraoral defects $(45.5 \%)$ after surgical removal of malignant tumours of the tongue (hemiglossectomy or near total glossectomy) plus modified lymph node neck dissection either unilateral or bilateral.

There were 6 cases with unilateral total facial nerve paralysis cases (house brakmann $6^{\text {th }}$ grade) and in the sixth case (the patient number 11) the facial nerve paralysis associated with soft tissue defect in the left parotid region due to iatrogenic injury (house brakmann $6^{\text {th }}$ grade).

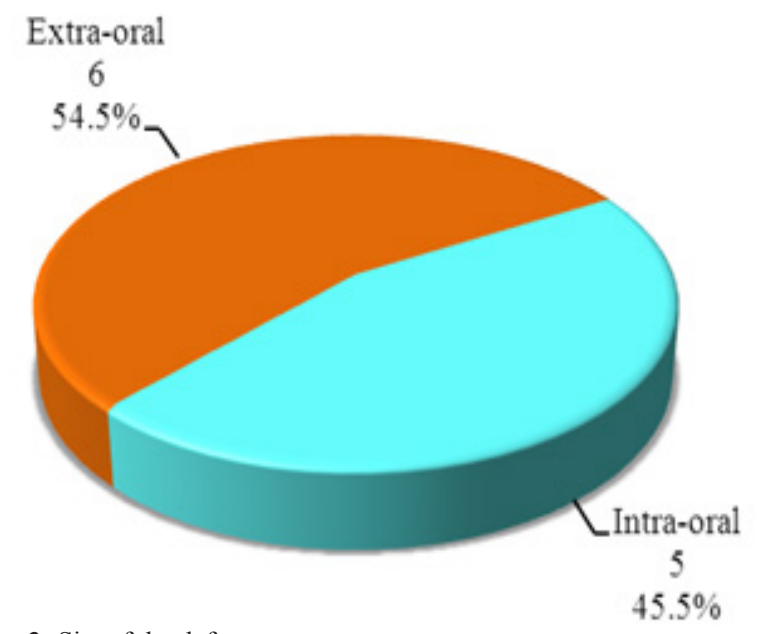

Figure 3: Site of the defect.

\section{Operative results:}

In this study, 11 cases of gracilis free flaps were successful to achieve the reconstructive goals (100\%).

As regards functional reconstruction the results will be discussed later.

\section{Donor site closure:}

All donor site were primarily closed.

\section{Site and types of microvascular anastomosis:}

End to end arterial anastomosis was done to the facial artery in all cases. The larger vena comitant with more venous return was used for the venous anastomosis i.e. one venous anastomosis. Venous anastomosis were with the facial vein end to end.

\section{Microneuro anastomosis:}

End to end nerve epineural anastomosis were done in six cases between motor nerve to gracilis muscle and motor nerve to masseter muscle using operating microscope.

In patient no. 11 microneuroanastomosis was done between motor nerve to gracilis and main trunk of facial nerve.

\section{Follow up results:}

The mean follow up period was one year.

\section{Subjective and Objective evaluation of Function and Aesthetics:}

The evaluation of function and aesthetic were directed to the 11 patients whose reconstruction involved oral and extraoral area.

\section{Function evaluation:}

A- Subjective: Swallowing in patients with malignant tumors of the tongue.

Only one patient had oral difficulty in swallowing (20\%) (One patient out of 5).

B- Objective: speech in patients with malignant tumors of the tongue.

Unintelligible speech was recognized one patient $(20 \%)$ (one patient out of five).

\section{Aesthetics:}

A- Subjective: Nine patients $(81.8 \%)$ were very satisfied, one patient was neutral $(9.1 \%)$, and one $(9.1 \%)$ was very unsatisfied with the aesthetic result of the oro-facial reconstruction.

B- Objective: In patients with facial reanimation

Flap bulkiness ( 1 patient out of six $16.7 \%$ ), 4 patients out of six patients were suffered from asymmetry of smile $66.7 \%$. 


\section{Complications:}

\section{Operative complications:}

There were no intraoperative deaths.

\section{- Intraoperative flap failure:}

None of operated cases suffered from intraoperative flap failure.

\section{- Arterial thrombosis:}

Intraoperative arterial thrombosis was recorded in patient number 11 .

Immediate revision of anastomosis and removal of thrombus was done with salvage of the flap.

\section{Postoperative complications:}

A- Early postoperative complications:

\section{Hematoma:}

Hematoma happened early on the first postoperative day only in one patient (patient no.1), and was resolved via conservative measures as close monitoring, antibiotics and hot fomentation after first 2 days postoperative, no need for secondary surgical intervention.

\section{Late postoperative complications:}

B- Late postoperative complications:

\section{Wound dehiscence:}

Two cases were suffered from wound dehiscence, gracilis myocutanous free flap were harvested in the two cases. The defects were in the horizontal part of donor site.

Both of them were managed conservatively by frequent dressings and close follow up three times per week till eventual healing.

\section{DISCUSSION}

The features that should constitute an ideal free flap for head and neck soft tissue reconstruction are:

- The tissue harvested should be pliable to restore the contour efficiently and not to impair movement and function in its new position in the head and neck.

- The vascular pedicle should be long, large and consistent.

- The surgical anatomy should be constant and reliable.

- Raising the flap should be simple; with short learning curve.

- Raising the flap should be possible in the supine position to permit synchronous harvest during head and neck surgery.

- The donor site morbidity should be low, both in terms of function and cosmesis.
- Sensate if possible $e^{[1]}$.

There may be no ideal free flap for head and neck reconstruction. Defects in this region can vary tremendously in composition and texture within short distances. This is particularly obvious in defects of the cranium, skull base, and midface. Therefore, the choice of free-tissue transfer should be tailored to the needs of the defect and limitations of each patient ${ }^{[2]}$.

Since its original description in 1982, the radial forearm free flap has become the workhorse microsurgical flap in head and neck reconstruction ${ }^{[3]}$. However, this flap does have its limitations. Whilst it possible to obtain good consistent results in the forearm in respect of closure of the donor site with either full thickness skin grafts, split skin grafts or transposition flaps, there will be exceptions when breakdown, keloid or hypertrophic scar occur. Also, if an extensive area of skin paddle is required, the donor site morbidity will increase as it will depend on the take of a large skin graft ${ }^{[4]}$.

For larger soft tissue defects, the subscapular system [scapular and latissimus dorsi] muscular or myocutaneous flaps have become more popular. The subscapular system provides good tissue bulk; however, it cannot be harvested synchronously during head and neck surgery as it requires patient repositioning for flap harvest. Muscle flaps also provide good tissue bulk; however, because they are not innervated, they usually tend to shrink with time, thus making the long-term results somewhat unpredictable ${ }^{[5]}$.

The free rectus abdominis muscle flap has been described as the workhorse in skull-base reconstruction. The bulk of this flap allows for the obliteration of large dead spaces; also, the muscle only can be used without the skin paddle, depending on the amount of bulk required. However, the flap is not without morbidity. Mizgala et al. ${ }^{[2]}$ defined the long-term consequences of the TRAM flap procedure. Their findings showed decreased abdominal strength and sit-up performance, asymptomatic bulging from the harvest site, abdominal laxity, and increased back pain.

Although the anterolateral thigh [ALT] flap has been described before ${ }^{[6]}$, the use of this flap in head and neck reconstruction has been largely popularized by Wei et al. ${ }^{[7]}$ It is suggested that suitable perforators are not available in less than $1 \%$ of cases. In the past, this figure was thought to be much higher and this is probably why the technique remained dormant for 2 decades ${ }^{[8]}$.

DIEP flap was first described by Koshima and Soeda ${ }^{[9]}$ and Koshima et al. ${ }^{[10]}$ in 1989. DIEP flaps were first described for breast reconstruction in 1994 by Allen and Treece, in an attempt to minimize the donor-site complications ${ }^{[11]}$. DIEP use for head and neck reconstruction is still not popular and there are few reports in the literature concerning its use for reconstructing this area ${ }^{[10]}$

When compared to the above mentioned freeflap options, gracilis myocutanous free flaps have distinct advantages: 
they allow harvesting larger and thicker skin paddles (mandatory when dealing with total/subtotal glossectomy or extensive maxillofacial defects) than a radial forearm free flap; they have a much more constant and reliable vascular anatomy when matched with the anterolateral thigh, they do not require patient's repositioning during surgery as in latissimus dorsi and parascapular free flaps, thus making the two-team approach feasible and without the morbidities found in the rectus abdominis flap.

In addition the hidden donor site with minimal morbidity is one of important advantages of gracilis myocutanous free flap.

In a study of 104 patients requiring gracilis flaps, only $6 \%$ of patients had persistent weakness that interfered with walking or running, and a $<10 \%$ donor site complication rate consisting of infection, bleeding, or pain $^{[13]}$.

Besides facial reanimation, gracilis myocutanous free flap has also been used to fill soft tissue defects in the head and neck, and has also been well served for aesthetic purposes ${ }^{[14]}$. Although more commonly taken as a muscular rather than myocutaneous flap because of the inconsistency of perforators, Yousif et al. ${ }^{[15]}$ have reported that a large skin paddle can be harvested with the muscle.

The gracilis free flap can be used alone or in combination with local flaps or grafts. Genden et al. ${ }^{[16]}$ reported on the use of a posterior scalp flap in conjunction with a gracilis free muscle flap for midface reconstruction. In 2005, Huemer et $a{ }^{\left[{ }^{[17]}\right.}$ reported the use of gracilis free flap in the reconstruction of 7 patients with buccal, temporal, and frontotemporal defects. Five patients had oncologic surgery and 2 had defects resulting from trauma. The gracilis free flap was used in conjunction with split and full thickness skin grafts, and the author reported optimal tissue transfer, aesthetics, and donor site outcome ${ }^{[17]}$.

The use of gracilis free flap for resurfacing parotid defects has also been reported. Braam et al. ${ }^{[18]}$ and Kropf et $a l^{\left[{ }^{19]}\right.}$ have reported reconstructing these defects successfully using gracilis flap for moderately sized defects, stating that a skin island can also be used for resurfacing external defects. The authors reported $100 \%$ flap survival with no donor or recipient site complications ${ }^{[18,19]}$.

Total or subtotal resection of the tongue leads to clinically significant swallowing and speech impairment. Numerous reconstructive techniques including local and free flaps have been advocated for tongue reconstruction after total or subtotal glossectomy ${ }^{[20]}$. The rectus abdominis myocutaneous [RAM] free flap is often used as it provides an adequate reconstruction volume ${ }^{[21]}$ the literature has revealed, there are few reports describing tongue reconstruction using the transverse gracilis myocutaneous [TMG] free flap ${ }^{[15]}$.

In our study, we had 11 patients in the period between September 2013 and December 2016, in five cases we used transverse myocutanous gracilis [TMG] flap for tongue reconstruction after radical resection of malignant tumors affecting the tongue, in three cases we had done near total glossectomy and in two cases patients had hemiglossectomy.

As mentioned before, in 5 patients, the defects resulted following radical surgery for locally advanced tongue tumors $[45.5 \%$ of total number of cases], where the surgical defects were beyond local or regional flaps reconstruction. The pathology of these tumours was squamous cell carcinoma in the five patients.

In one case we had used gracilis myocutanous for resurfacing of parotid defect post resection of vascular lesion affecting the parotid region.All flaps survived and succeded to reconstruct the soft tissue defects.

According TNM classification ${ }^{[22]}$, we had one patient suffered from $\mathrm{T} 3$ tumor, and four patients had T4a tumors. But we had two patients with $\mathrm{N} 1$ and the other three patients had N0, N2b and N2c lymph node metastasis. All patients had no distant metastasis (M0).

We had reconstructed the defects after radical resection by transverse myocutanous gracilis free flap, the sizes of skin paddles ranged from $5 \times 7 \mathrm{~cm}\left(35 \mathrm{~cm}^{2}\right)$ to $8 \times 10 \mathrm{~cm}\left(80 \mathrm{~cm}^{2}\right)$. The largest flap was used to reconstruct tongue after near total glossectomy plus reconstruction of floor of the mouth in patient no.1.

In our study we had measured the incidence of complications, None of operated cases suffered from intraoperative flap failure. Intraoperative arterial thrombosis recorded in patient number 11 . Immediate revision of anastomosis and removal of thrombus was done with salvage of flap. Hematoma was happened early postoperative only in one patient (patient no.1), and resolved via conservative measures as close monitoring, antibiotics and hot fomentation after first 2 days postoperative.

Two cases gracilis myocutanous free flap suffered from wound dehiscence. The defects were in the horizontal part of donor site. Both of them were treated conservatively with frequent dressings and close follow up three times per week till complete healing.

All patients followed up to one year, out of the five cases that were reconstructed for tongue defects, only one patient had oral difficulty in swallowing (20\%) (One patient out of 5) and another one suffered from severe difficulty in speech (20\%) (One patient out of five).

Clinical follow-up in their study ranged from 6 to 28 months with an average of 15 months. The transverse myocutanous gracilis free flap provided good tongue contour with sufficient bulk following total glossectomy .Volumetrically the flaps remained stable during the follow-up period without clinical atrophy in all patients, and no voluntary movements of the reconstructed tongue observed. All patients recovered intelligible speech ${ }^{[23]}$. 
Yoleri et al. ${ }^{[24]}$ described the innervated gracilis myocutaneous flap to reconstruct a total glossectomy defect. The muscle was placed longitudinally and anchored from the remaining tongue base and pharynx to the mandible, it was folded onto itself and suspended to the hyoid bone. The patient was able to resume oral feeding without aspiration, where was the nerve anastomosis ${ }^{[24]}$.

Kropf et al. ${ }^{[19]}$ reported on a clinical case where the TMG flap was used to reconstruct a partial glossectomy defect; however, the postoperative functional results were not described in detail. Yu and Robb ${ }^{[25]}$ presented a series of 94 defects after total or near-total glossectomy reconstructed with different flaps including two cases that employed the gracilis flap. The authors suggested that all patients who had undergone postoperative radiotherapy showed significant atrophy and fibrosis of the reconstructed tongue ${ }^{[25]}$.

The most commonly used motor nerve substitutes are the contralateral facial nerve, motor nerve to the masseter muscle, and the hypoglossal nerve. Methods that reinnervate native facial muscles in a timely matter are preferred if possible, as no other skeletal muscle can adequately simulate the complex morphology and organization of facial mimetic muscles. However, when native muscles are congenitally absent or are irreversibly paralyzed because of prolonged denervation, regional muscle transfer (ie, temporalis tendon transfer) or free muscle transfer (i.e, microvascular gracilis muscle transfer) can be used to replace muscle function in dynamic reanimation. Static suspension techniques, nonsurgical procedures such as chemodenervation, and physical therapy are useful adjuvant and, sometimes, primary treatment.

options for some patients. The duration of facial muscle denervation and timeliness of intervention are perhaps the most important factors that determine the ultimate success of any reinnervation procedure ${ }^{[26]}$.

Patient age has also been shown to be an important factor influencing outcomes, with elderly age associated with poorer results. The age-related decline in neural regeneration is well established and thought to be multifactorial, secondary to myelin sheath deterioration, axonal atrophy, decline in nerve conduction, and slower rate of axonal regeneration ${ }^{[27]}$.

When facial nerve paralysis is established [conventionally defined as lasting for more than 18 months] neuromuscular transplantations are nowadays considered as the gold-standard procedures, and gracilis muscle transplant is the most commonly used technique worldwide ${ }^{[28]}$.

The key point, and most debated topic of the procedure, is the selection of the donor nerve for reinnervation of the transplant: contralateral facial nerve via cross-graft technique, masseteric nerve, and combined techniques are the procedures usually performed by the largest majority of authors ${ }^{[29]}$.
When unilateral forms are treated, in order to achieve a spontaneous activation of the transplanted muscle, the use of contralateral healthy facial nerve via a cross-graft procedure is worldwide considered as the best option in the majority of patients, whereas the masseteric nerve use is usually reserved for selected cases including elderly patients, salvage surgeries after previous cross-graft failures, incomplete bilateral palsies when contralateral facial nerve is not completely healthy, or in combination with a cross-graft to provide a dual innervation to the transplant ${ }^{[30]}$.

In our study, we had done six cases suffered from total facial nerve paralysis for facial reanimation, all cases were assessed according to House-Brackmann Classification ${ }^{[31]}$ of Facial Function.

6 patients suffered from unilateral total facial nerve paralysis $(54.5 \%), 3$ patients were caused by bell's palsy, 2 patients were caused by iatrogenic injury after excision of glomus tympanicum and one patient $(9.1 \%)$ was suffered from left facial nerve paralysis and soft tissue defect of left parotid region due to iatrogenic injury after surgical excision of a vascular lesion.

End to end nerve anastomosis were done in five cases between motor nerve to gracilis muscle and motor nerve to masseter muscle and in the sixth case we had done microneuroanastomosis between motor nerve to gracilis and main trunk of facial nerve.

The critical factor is to reduce bulk. We do this by only using a small segment of the gracilis muscle, approximately $1 / 3$ of the circumference. We also remove the buccal fat pad.

We provide a strong motor input by anastomosis nerve to gracilis to nerve to masseter.We utilized the motor nerve to masseter in all cases, which provides enough power for normal muscle excursion. Another key of success is to provide appropriate tension on the muscle. This involves placing the muscle under a slight degree of tension so that the commissure just barely moves.

Our results were assessed objectively and subjectively in relation to functional and aesthetic outcomes.

We had one case suffered from Flap bulkiness (1 patient out of six $16.7 \%$ ), and 4 patients out of six patients suffered from asymmetry of smile $66.7 \%$, but patients are satisfied about the obtained results except for one case that doesn't restore acceptable smile (one patient out of six failed to restore smile $17.7 \%$ ) due to inappropriate tension on gracilis muscle.

Zuker et al. ${ }^{[32]}$ found that in bilateral facial paralysis, there was no facial nerve available, and consequently, the cross face nerve graft procedure was not possible. In these situations, they had found the segmental gracilis muscle transplant to be most useful. However, it need to be innervated by a different motor nerve. They had tried various motor nerves, such as the hypoglossal, the 
accessory, but felt that the motor nerve to masseter is by far the best. It was a powerful nerve that provided excellent excursion to the muscle transplant. They found it also was in a better position to allow for spontaneity through cortical plasticity.

In 1998, Harii et al. ${ }^{[33]}$ proposed a new surgical technique to harvest the latissimus dorsi flap. In adult patients, 15 to $16 \mathrm{~cm}$ of the dorsal nerve are harvested via a proximal dissection of the thoracodorsal nerve until its origin from the posterior chorda of the brachial plexus and the distal dissection of the muscle parenchyma.

Biglioli $\mathrm{F}$ et $a l^{[34]}$ found this length is suitable to anastomose the nerve to one or more branches of the contralateral facial nerve for the musculus zygomaticus major. This surgical step is essential to ensure that the correct stimulus is used, as the nerve branches for that muscle are invariably involved in smiling. During the surgical procedure, the selected branch of the facial nerve is evaluated by electro stimulation and.nevertheless, in two cases, we observed the need for the patient to partially contract the contralateral eye to activate the flap, most likely because a part of the donor nerve fibers destined to the orbicularis oculi ${ }^{[34]}$.

Single-stage facial reanimation has been proposed to reduce the time required for treatment and recovery ${ }^{[35]}$. The single-stage procedure involves one nerve anastomosis instead of two, as required by the two-stage technique with cross-face nerve grafting. Theoretically, this would guarantee the passage of a larger number of nerve fibers, though results are not better than those of most two-stage techniques ${ }^{[36]}$.

In 1978, Spira ${ }^{[37]}$ first reported the use of the motor nerve to the masseter muscle for facial reanimation. It was initially popularized for reinnervation of free muscle transfers and, over the past decade, has increasingly become the technique of choice for direct neurotization ${ }^{[38]}$.

Because of its proximity and similar diameter to the facial nerve, the masseteric nerve can be directly anastomosed to the facial nerve without the use of an interposition graft. ${ }^{[39]}$. It is a rich source of myelinated motor fibers; although the absolute count depends on the method of histomorphometric analysis, Coombs and colleagues ${ }^{[40]}$ showed that the masseteric nerve contains 1542 myelinated fibers compared with 834 fibers in a buccal branch.. Also given the close proximity, rapid tone and motion recovery are expected within 3 to 6 months postoperatively.

There is limited donor site morbidity. Functional loss from partial denervation of the masseter muscle is minimal as the masseter and temporalis muscles work together in mastication and only the descending branch is divided, leaving the more proximal branches intact ${ }^{[41,42]}$.

The subzygomatic triangle using the zygomatic arch, temporomandibular joint, and the frontal branch of the facial nerve provides a rapid method for identifying the nerve with minimal dissection ${ }^{[33]}$.

Lastly, studies suggest a connectedness between the trigeminal and facial nuclei and nerves that seems to contribute to the ease of cerebral adaptation after $\mathrm{CN} V$ to VII transfer ${ }^{[44-46]}$. This finding may be partly explained by the fact that in $40 \%$ of adults, natural masseter contraction occurs during normal smile ${ }^{[46]}$. Most patients following masseteric nerve transfer seem to be able to develop an effortless smile without clenching their teeth.

Klebuc $^{[46]}$ reported $75 \%$ of patients following masseteric nerve transfer developed an effortless smile without teeth clenching after 2 or more years of follow-up.

In another study whereby the masseteric nerve was used as the donor for gracilis free muscle transfer, Manktelow and colleagues ${ }^{[47]}$ found that $59 \%$ of patients could smile effortlessly without conscious effort and $85 \%$ of patients could smile without teeth clenching.

In our study, we do agree with the results in the literature as regards spontaneous smile without conscious effort as we have 4 patients in this study $(66.7 \%)$ and after one year 5 patients $(83.3 \%)$ could smile without teeth clenching.

The main disadvantage of the masseteric nerve transfer is that although the smile that frequently evolves is effortless or reflexive, it is not truly spontaneous or emotionally mediated and often requires a significant amount of patient motivation for facial neuromuscular retraining therapy. Minor donor complications, such as slight weakness with mastication, masseteric atrophy with resultant cosmetic deformity, and facial twitching with mastication, have been reported, although none seem to produce any quality-oflife implications ${ }^{[48]}$.

In our study we believe that the atrophy of the masseter muscle is mimicked by the overlying transplanted gracilis muscle.

Dual innervation of free muscle transfers with both the masseteric nerve and cross facial nerve graft has been suggested to optimize both strength and spontaneity of movement .Watanabe and colleagues ${ }^{[49]}$ first reported the use of 1-stage free muscle transfer with double innervation for reanimation of long-standing facial paralysis; their study demonstrated improvement in latissimus dorsi muscle contraction by positioning the hilum of the flap in contact with a part of the denuded masseter on the paralyzed side.

Several recent studies using dual innervation have shown good to excellent outcomes in symmetry at rest as well as volitional/spontaneous movement ${ }^{[50,51]}$. Similar questions arise: Is 1-stage versus 2-stage more preferable? What is the ideal coaptation pattern? Biglioli and colleagues ${ }^{[50]}$ and Sforza and colleagues ${ }^{[52]}$ described a similar 1-stage procedure whereby the ipsilateral masseteric nerve is coapted by end-to-end neurorrhaphy to 
the obturator nerve and the contralateral, intact facial nerve is coapted end-to-end with a cross facial nerve graft on the healthy side, which is coapted end-to-side on the obturator nerve, distal to the masseteric obturator anastomosis.

In the Sforza study ${ }^{[52]}$, a 3-dimensional optoelectronic motion analyzer was used to find that following dual innervation gracilis surgery, $75 \%$ of the normal spontaneous smile was achieved on the paretic side, which increased to $91 \%$ when teeth clenching was added, with less than $20 \%$ asymmetry.

Despite dual innervation improves quality of smile yet our experience from this study reveals facial reanimation with gracilis free flap and anastomosis with nerve to masseter muscle gives a powerful input to transferred muscle and spontaneous smile gained in patients by time without clenching.

From previous discussion we believe that the complexity of facial expression and synergy of facial muscles is difficult to be fully restored, the ultimate goal of facial paralysis treatment is to reestablish facial symmetry and movement. Tremendous progress in dynamic facial reanimation options and outcomes has been made over the past couple of decades, but contemporary management remains fraught with debate.

Advances in surgical techniques as well as the consistent use of outcome reporting measures across facial paralysis specialists will guide the evolving evidencebased approach to facial reanimation.

The future holds additional promise with developing advances in tissue engineering and neural regeneration as well as emerging technologies in bioelectrical interfaces ${ }^{[53]}$.

\section{CONFLICT OF INTEREST}

The authors declare no conflict of interest.

\section{REFERENCES}

1. Eckardt A, Meyer A, Laas U, Hausamen JE. Reconstruction of defects in the head and neck with free flaps: 20 years experience. Br J Oral Maxillofac Surg. 2007; 45 (1): 11 - 5.

2. Morris DM UG. Use of flaps in reconstructive surgery of the head and neck, in Peterson LJ (ed): Principles of Oral and Maxillofacial Surgery: Philadelphia, PA, Lippincott; 1992. 947 p.

3. Bakamjian VY. A Two-Stage Method for Pharyngoesophageal Reconstruction with a Primary Pectoral Skin Flap. Plast Reconstr Surg. 1965; 36: 173 - 84.

4. Andrews BT, McCulloch TM, Funk GF, Graham SM, Hoffman HT. Deltopectoral flap revisited in the microvascular era: a single-institution 10-year experience. Ann Otol Rhinol Laryngol. 2006; 115 (1): 35 - 40 .

5. El-Marakby HH. The reliability of pectoralis major myocutaneous flap in head and neck reconstruction. J Egypt Natl Canc Inst. 2006; 18 (1): 41 - 50.

6. Ariyan S. The pectoralis major myocutaneous flap. A versatile flap for reconstruction in the head and neck. Plast Reconstr Surg. 1979; 63 (1): 73 - 81.

7. Nakajima H, Fujino T, Adachi S. A new concept of vascular supply to the skin and classification of skin flaps according to their vascularization. Ann Plast Surg. 1986; 16 (1): 1 - 19.

8. Neligan PC. Head and neck reconstruction. Plast Reconstr Surg. 2013; 131 (2): 260e - 9e.

9. Mathes SJ, Nahai F. Reconstructive surgery: principles, anatomy \& technique: Churchill Livingstone; 1997.

10. Cavadas PC, Sanz-Gimenez-Rico JR, Landin L, Martinez-Soriano F. Segmental gracilis free flap based on secondary pedicles: anatomical study and clinical series. Plast Reconstr Surg. 2004; 114 (3): 684 - 91.

11. Schusterman MA, Miller MJ, Reece GP, Kroll SS, Marchi M, Goepfert H. A single center's experience with 308 free flaps for repair of head and neck cancer defects. Plast Reconstr Surg. 1994; 93 (3): 472 - 8; discussion 9 - 80

12. Wechselberger G, Schoeller T. The transverse myocutaneous gracilis free flap: a valuable tissue source in autologous breast reconstruction. Plast Reconstr Surg. 2004; 114 (1): 69 - 73.

13. Carr MM, Manktelow RT, Zuker RM. Gracilis donor site morbidity. Microsurgery. 1995; 16 (9): 598 - 600.

14. Wong $\mathrm{CH}$, Wei FC. Microsurgical free flap in head and neck reconstruction. Head \& neck 2010; 32 (9): 1236 - 45 .

15. Yousif NJ, Dzwierzynski WW, Sanger JR, Matloub HS, Campbell BH. The innervated gracilis musculocutaneous flap for total tongue reconstruction. Plastic and reconstructive surgery. 1999; 104 (4): 916 - 21.

16. Genden EM, Mandell D, Urken ML. The combination of posterior scalping flap and gracilis 
free flap for mid-face reconstruction. Operative Techniques in Otolaryngology-Head and Neck Surgery. 2000; 11 (2): 72 - 5 .

17. Huemer GM, Bauer T, Wechselberger G, Schoeller T. Gracilis muscle flap for aesthetic reconstruction in the head and neck region. Microsurgery. 2005; 25 (3): 196 - 202.

18. Braam M, Meland N, Olsen $\mathrm{K}$. The gracilis free flap for reconstruction of parotidectomy defects. European Journal of Plastic Surgery. 1994; 17 (5): 243 - 6.

19. Kropf N, Cordeiro CN, McCarthy CM, Hu QY, Cordeiro PG. The vertically oriented free myocutaneous gracilis flap in head and neck reconstruction. Annals of plastic surgery. 2008; 61 (6): 632 - 6 .

20. Haddock NT, DeLacure MD, Saadeh PB. Functional reconstruction of glossectomy defects: the vertical rectus abdominus myocutaneous neotongue. Journal of reconstructive microsurgery. 2008; 24 (5): 343 - 50.

21. Yamamoto Y, Sugihara T, Furuta Y, Fukuda S. Functional reconstruction of the tongue and deglutition muscles following extensive resection of tongue cancer. Plastic and reconstructive surgery. 1998; 102 (4): 993 - 8; discussion 9 - 1000 .

22. Schusterman MA, Miller MJ, Reece GP, Kroll SS, Marchi M, Goepfert H. A single center's experience with 308 free flaps for repair of head and neck cancer defects. Plastic and reconstructive surgery. 1994; 93 (3): 472 - 8; discussion 9 - 80.

23. Calabrese L, Saito A, Navach V, Bruschini R, Saito N, Zurlo V, et al. Tongue reconstruction with the gracilis myocutaneous free flap. Microsurgery. 2011; 31 (5): 355 - 9.

24. Yoleri L, Mavioglu H. Total tongue reconstruction with free functional gracilis muscle transplantation: a technical note and review of the literature. Annals of plastic surgery. 2000; 45 (2): 181 - 6.

25. Yu P, Robb GL. Reconstruction for total and near-total glossectomy defects. Clinics in plastic surgery. 2005; 32 (3): 411 - 9, vii.

26. Terzis JK, Konofaos P. Nerve transfers in facial palsy. Facial plastic surgery: FPS. 2008; 24 (2): 177 - 93.
27. Verdu E, Ceballos D, Vilches JJ, Navarro X. Influence of aging on peripheral nerve function and regeneration. Journal of the peripheral nervous system : JPNS. 2000; 5 (4):191 - 208.

28. Bhama PK, Hadlock TA. Contemporary facial reanimation. Facial plastic surgery: FPS. 2014; 30 (2): 145 - 51.

29. Faria JC, Scopel GP, Busnardo FF, Ferreira MC. Nerve sources for facial reanimation with muscle transplant in patients with unilateral facial palsy: clinical analysis of 3 techniques. Annals of plastic surgery. 2007; 59 (1): 87 - 91.

30. Bianchi B, Ferri A, Ferrari S, Copelli C, Salvagni L, Sesenna E. The masseteric nerve: a versatile power source in facial animation techniques. The British journal of oral \& maxillofacial surgery. 2014; 52 (3): 264 - 9.

31. House JW, Brackmann DE. Facial nerve grading system. Otolaryngology--head and neck surgery : official journal of American Academy of Otolaryngology-Head and Neck Surgery. 1985; 93 (2): $146-7$.

32. Zuker RM, Goldberg CS, Manktelow RT. Facial animation in children with Mobius syndrome after segmental gracilis muscle transplant. Plastic and reconstructive surgery. 2000; 106 (1): 1 - 8; discussion 9.

33. Harii K, Asato H, Yoshimura K, Sugawara Y, Nakatsuka T, Ueda K. One-stage transfer of the latissimus dorsi muscle for reanimation of a paralyzed face: a new alternative. Plastic and reconstructive surgery. 1998; 102 (4): 941 - 51.

34. Biglioli F, Frigerio A, Rabbiosi D, Brusati R. Single-stage facial reanimation in the surgical treatment of unilateral established facial paralysis. Plastic and reconstructive surgery. 2009; 124 (1): 124 - 33.

35. Kumar PA, Hassan KM. Cross-face nerve graft with free-muscle transfer for reanimation of the paralyzed face: a comparative study of the single-stage and two-stage procedures. Plastic and reconstructive surgery. 2002; 109 (2): 451 - 62; discussion $63-4$

36. Harii K. Experimental and clinical studies of nerve and muscle grafts for the treatment of facial paralysis. J Jpn Plast Reconstr Surg. 1987; 7 (347): e72. 
37. Spira M. Anastomosis of masseteric nerve to lower division of facial nerve for correction of lower facial paralysis. Preliminary report. Plastic and reconstructive surgery. 1978; 61 (3): 330 - 4.

38. Klebuc M. Masseter-to-Facial Nerve Transfer: A New Technique for Facial Reanimation. Journal of reconstructive microsurgery. 2006; 22 (03): A101.

39. Cotrufo S, Hart A, Payne AP, Sjogren A, Lorenzo A, Morley S. Topographic anatomy of the nerve to masseter: an anatomical and clinical study. Journal of plastic, reconstructive and aesthetic surgery : JPRAS. 2011; 64 (11): 1424 - 9.

40. Coombs CJ, Ek EW, Wu T, Cleland H, Leung MK. Masseteric-facial nerve coaptation--an alternative technique for facial nerve reinnervation. Journal of plastic, reconstructive \& aesthetic surgery : JPRAS. 2009; 62 (12): 1580 - 8 .

41. Borschel GH, Kawamura DH, Kasukurthi R, Hunter DA, Zuker RM, Woo AS. The motor nerve to the masseter muscle: an anatomic and histomorphometric study to facilitate its use in facial reanimation. Journal of plastic, reconstructive and aesthetic surgery: JPRAS. 2012; 65 (3): $363-6$.

42. Hwang K, Kim YJ, Chung IH, Song YB. Course of the masseteric nerve in masseter muscle. The Journal of craniofacial surgery. 2005; 16 (2): 197 - 200.

43. Collar RM, Byrne PJ, Boahene KD. The subzygomatic triangle: rapid, minimally invasive identification of the masseteric nerve for facial reanimation. Plastic and reconstructive surgery. $2013 ; 132(1): 183-8$

44. Rubin LR, Rubin JP, Simpson RL, Rubin TR. The search for the neurocranial pathways to the fifth nerve nucleus in the reanimation of the paralyzed face. Plastic and reconstructive surgery. 1999; 103 (6): $1725-8$

45. Lifchez SD, Matloub HS, Gosain AK. Cortical adaptation to restoration of smiling after free muscle transfer innervated by the nerve to the masseter. Plastic and reconstructive surgery. 2005; 115 (6): 1472 - 9.
46. Klebuc MJ. Facial reanimation using the masseterto-facial nerve transfer. Plastic and reconstructive surgery. 2011; 127 (5): 1909 - 15.

47. Manktelow RT, Tomat LR, Zuker RM, Chang M. Smile reconstruction in adults with free muscle transfer innervated by the masseter motor nerve: effectiveness and cerebral adaptation. Plastic and reconstructive surgery. 2006; 118 (4): 885 - 99.

48. Wang W, Yang C, Li Q, Li W, Yang X, Zhang YX. Masseter-to-facial nerve transfer: a highly effective technique for facial reanimation after acoustic neuroma resection. Annals of plastic surgery. 2014; 73 Suppl 1:S63 - 9.

49. Watanabe Y, Akizuki T, Ozawa T, Yoshimura K, Agawa K, Ota T. Dual innervation method using one-stage reconstruction with free latissimus dorsi muscle transfer for re-animation of established facial paralysis: simultaneous reinnervation of the ipsilateral masseter motor nerve and the contralateral facial nerve to improve the quality of smile and emotional facial expressions. Journal of Plastic, Reconstructive \& Aesthetic Surgery. 2009; 62 (12): 1589 - 97.

50. Biglioli F, Colombo V, Tarabbia F, Pedrazzoli M, Battista V, Giovanditto F, et al. Double innervation in free-flap surgery for longstanding facial paralysis. Journal of plastic, reconstructive and aesthetic surgery: JPRAS 2012; 65 (10): 1343 - 9 .

51. Cardenas-Mejia A, Covarrubias-Ramirez JV, Bello-Margolis A, Rozen S. Double innervated free functional muscle transfer for facial reanimation. Journal of plastic surgery and hand surgery. 2015; 49 (3): 183 - 8.

52. Sforza C, Frigerio A, Mapelli A, Tarabbia F, Annoni I, Colombo V, et al. Double-powered free gracilis muscle transfer for smile reanimation: A longitudinal optoelectronic study. Journal of plastic, reconstructive \& aesthetic surgery : JPRAS. 2015; 68 (7): 930 - 9.

53. Langhals NB, Urbanchek MG, Ray A, Brenner MJ. Update in facial nerve paralysis: tissue engineering and new technologies. Current opinion in otolaryngology and head and neck surgery. 2014; 22 (4): 291 - 9. 